\title{
GENDER-BASED DISCRIMINATION IN NURSING: A GHANAIAN PERSPECTIVE
}

\author{
DF Ofori, University of Ghana Business School
}

Purpose and objectives: The 'glass escalator' phenomenon holds that men in female dominated professions like nursing can rise quickly to the top. However, they can also suffer discrimination. This phenomenon is widely recognised in advanced countries. Trained, mostly female nurses have been leaving Ghana in droves for greener pastures abroad, particularly the US and UK, with serious consequences on the health delivery service in Ghana. Conversely, increasing numbers of males are joining the nursing profession. It examines whether male nurses in Ghana enjoy any hidden advantages, and if so, what makes the men successful (even with their limited numbers) in a women-dominated field and what the implications are for both male and female nurses.

Problem investigated: The article explores gender-based discrimination and the phenomenon of the glass escalator in a developing country context. It examines the position of male nurses in Ghana; the type, nature and extent of advantages they enjoy and any discrimination they face in a female-dominated field.

Methodology: An in-depth cross-sectional questionnaire was employed. A thematic and cluster analysis of findings was executed, with data captured using Statistical Package for Social Sciences (SPSS). A combination of descriptive accounts as well as summary statistics using chi-square and correlations was used to examine the findings.

Findings and implications: This paper reports the findings of an empirical study that show that male nurses neither suffer gender-based discrimination nor occupy the top positions in the nursing field. It also found that a majority of males do not want to leave the profession even though they feel they are assigned more responsibilities and are sometimes passed over for promotion.

Originality: Whilst representing a modest contribution to research in gender-based discrimination in nursing, this paper is a first attempt to investigate the phenomenon in a Ghanaian context, with the dearth of relevant research in an area of increasing importance in Ghana serving as a huge fillip.

Key words and phrases: glass escalator, gender-based discrimination, nursing, Ghana

\section{INTRODUCTION}

Gender issues in the area of equal employment opportunity transcend national boundaries, and are usually debatable, depending on the focus and orientation of the research. It is becoming increasingly recognised that work and family domains have reciprocal effects on each other, and that one's work life cannot be understood outside the context of the family (Watson, 1995).

It is worthy to note that, when an organisation has to select among applicants for a job, it is largely because it is dealing with people whose productive capacities differ on various dimensions, and are largely unknown. Moreover, it is common knowledge that workers differ in age, gender, racial origin, intelligence, manual dexterity, physical strength and energy, work motivation, and other characteristics such as type of formal education, years of work experience and amount of specific job training, all of which affect productivity on the job.

For sometime now, the attention of many researchers has been focused on the issue of the male-female ratio in the workplace being in favour of males, and efforts are being made to bring some fairness in the employment system, especially, to creating conducive environments for females to enter male dominated fields. However, historical events indicate that women dominate the nursing profession, with very few men trying to find their feet (Theweleit, 1987). What are the ramifications now that more men are developing their careers along the nursing profession? Are men likely to "hit" the invisible glass ceiling 
beyond which they cannot progress? Or will they be at an advantage in this profession (nursing) just as it is perceived to be happening in "male-dominated" professions?

\section{OBJECTIVES/PURPOSE}

This paper, one of the first of its kind in Ghana, examines whether male nurses in Ghana enjoy any hidden advantages, and if so, what makes the men successful (even with their limited numbers) in a women-dominated field. What are the implications for both male and female nurses? The research sought to examine whether:

- Men face or encounter any restrictions to their entry into the field of nursing in Ghana

- Male nurses are given more responsibilities at work than their female colleagues solely on the basis of their gender

- Male and female nurses enjoy equal career advancement opportunities

- Male nurses discriminated against in any way

- Male nurses intend to leave the profession at any point in the future.

The justification for the study is derived from a number of sources: the increasing concern expressed by policy makers about the downward trend of nurse enrolment in the various nursing training institutions in the country; the falling number of nurses engaged by the Ministry of Health against the backdrop of rising numbers of healthcare facilities; shortages of nurses being experienced by hospitals in Ghana; the anecdotal evidence that points to the increasing fascination with emigration by nurses in Ghana to greener pastures abroad, particularly to the US and UK; and the rising number of male nurses within the profession in Ghana. The literature has shown that there has for a long time existed a traditional view that nursing is a woman's work.

However, if fewer female trained nurses are remaining in the profession, more nursing positions are opening up and increasing numbers of males are choosing to go into nursing, what would be the implications for human resource management and policy direction within the profession in Ghana? The study was not aimed at identifying any new workplace models. It rather sought to confirm and document the existence, extent of recognition, nature and content of the glass escalator phenomenon in a female dominated profession - nursing - in Ghana. The objective of the study therefore, was to capture what male nurses do, how they affect their workplace, how the workplace also affects them and the implications for them and their various publics.

\section{PROBLEM INVESTIGATED}

Although no formal distinctions are made between jobs for men and women, there is a fairly clear segmentation of the labour market in most countries. Attempts are being made, however, to bridge the gap. For instance, it has been found that governments and women's organisations have realised the role of education in creating awareness and are making impressive strides at helping make gender stereotype a thing of the past (Abdul-Nasiru \& Cofie, 2002). But just how far has there been progress in this course? Research findings reveal varied results, especially with regard to the male-female ratio in the nursing profession.

The Hansard Society (1990) cited by Cox and Cooper (1997) report that $70 \%$ of women worked in lowerlevel clerical and service sector jobs. Very few women were found in the top-level positions of management and decision-making. In other words, in any given occupation, the higher the rank, the lower the proportion of women represented there. The opportunities for women to attain higher positions at their workplaces raise an appropriate need to investigate the internal dynamics of their career, especially where they are dominated as they strive for top jobs.

Moreover, much career advancement research has focused on the role of certain variables such as human capital (e.g. experience, training), interpersonal resources (mentor, network support), and family (e.g. employed spouse, dependents) for explaining differences in management advancement for male 
versus female managers (e.g. Kirchmeyer 1998, Stroh et al., 1992 and Tharenou et al., 1994). Hence, it is clear that workplace relationships have been explored in depth by many authors.

The twin concepts of the 'glass ceiling' and glass escalator' have both enjoyed a large measure of historical and contemporary research. Historically, Gamarnikow (1978:77-121) considered the sexual division of labour in nursing; according to Theweleit (1987) historical events indicate that women have dominated the nursing profession, with very few men trying to find their feet; Summers (1988) explored the role of British women as military nurses. Contemporary research has, however, considered in the main, the presumed relative advantages faced by men working in female-dominated fields. Williams, 1992, 1993, 1995; RBI, 1999; Maume, 1999; Hultin, 2003; Armour, 2003 and Callah, 2004; all articulating scholarly positions on various aspects of the phenomena. However, almost all the studies recorded in the literature have focused on North American and European economies. The literature on the phenomenon of the glass escalator in West Africa and Ghana is underdeveloped and this study represents one of the attempts at beginning to fill this research gap.

\section{LITERATURE REVIEW}

\section{Men in Female-Dominated Professions}

Research on women in male-dominated professions has found a "glass-ceiling"; a level above which women cannot rise due to discrimination. Williams (1995) did not find this effect for men in femaledominated professions. Instead, these men experienced a "glass escalator" that pushed them upwards in their professions. Williams $(1989,1992,1993,1995)$ argued that male nurses, elementary school teachers, librarians, social workers and so forth are able to ride a 'glass escalator' up internal career ladders to an extent and at a speed that their female co-workers can hardly enjoy. Lindgren (1992) also provides examples from the Swedish health sector. However, although Williams' studies suggest that men seem to be pushed upward, getting promoted in these professions, there is no available literature on the Ghanaian situation. Hence, it is difficult to say whether clear-cut advantages exist for men over their female counterparts.

According to Williams (1992), many men in female-dominated lines of work report that their minority status is an advantage in hiring and promoting situations. Maume (1999) notes that within femaledominated organisations, males still have the advantage in management and that they seem to bullet up the glass escalator. White (1995) also found that men who work in typically "female" occupations have substantially better internal promotion chances than equally qualified women in such occupations. It appears that women seem to be the ones who face limited opportunity for advancement even in femaletype lines of work. Many men are able to circumvent the obstacles to internal career growth in such settings. This finding is compatible with the idea that a so-called glass escalator takes underrepresented men on an upwardly mobile internal career path at a speed that their female colleagues can hardly enjoy. Furthermore, the results indicate that though men and women have equal internal career chances in male-dominated occupations, it is the men who advance. But surprisingly, the common assumption that obstacles to women's internal career growth are especially severe in men-dominated fields of work obtains no support. According to Reed Business Information (1999), much has been made of the glass ceiling for women in senior management positions but the argument is not so much of glass ceiling as a glass escalator.

\section{Challenges Faced by Men in Female-Dominated Professions}

Mounting research shows that men in predominantly female careers face gender discrimination, job discrimination and high rates of job-related stress (Armour, 2003). Much of the discrimination that men face in the nursing profession could actually be attributed to a larger societal gender bias. They are entering a profession traditionally dominated by women and face many of the same constraints that women have historically faced in entering workplaces dominated by men. 
The 'glass escalator' phenomenon holds that men tend to rise to the top of their occupations more quickly than their female counterparts. However, there has been an increasing realisation that while men benefit from taking their gender advantage into female occupations, they also suffer several challenges to their masculinity, both through working alongside women and, from performing roles regarded by society as one which women normally undertake (Vail, 1999). According to Williams (1992), men identified working in a female-dominated profession as a stigma. Others also opined that, unlike women who entered traditionally male professions, men's movement into female-dominated jobs is perceived by the 'outside world' as a step down in status.

Men face the challenge of unequal treatment at the workplace in female dominated professions. Williams (2006) found that, many male nurses are denied the opportunity to work in certain areas in hospitals, such as labour and delivery units or nursery units; whilst Chung (2006) asserts that quite a number of men are denied the opportunity to work in certain areas of their responsibilities. In addition, male nurses find that their female colleagues automatically expect them to handle unruly or heavy patients (Williams, 2006).

Most men engaged in women dominated professions are confronted by stereotypes every day. People act surprised when they learn about their profession. This brings about worry sometimes to these men in relation to the effects their gender may have on their career path. Chung (2006) argues that the best way to encourage men in women dominated professions is to speak well of the respective jobs. Hodes Research (2005:131) for instance, quotes a male nurse's perspective of nursing, 'nursing is not valued, it is perceived as a female role.' Language, symbols and policies all need to give each person a full and fair chance at success or failure. Gender-related management issues are also a common problem. Williams (2006) notes that some men have trouble accepting a female authority figure and some females have trouble managing men. This can be especially significant in a hospital setting, for according to the US Department of Labor (1997) cited by Jackson (2001), women hold 75\% of all managerial positions in medicine and healthcare.

\section{Human Resource Implications of Challenges Faced by Men in Female-Dominated Professions}

There is also the challenge of discrimination in salaries irrespective of the workload and unequal opportunities for promotion. Male nurses for example are not given equal opportunity to move up in the ranks or are being denied equal employment opportunities (Chung, 2006). Male elementary school teachers are in the minority at their schools and in their profession. Men who want to teach young children face questions about their motives and their masculinity. Male elementary school teachers are paid less and have less prestige than male teachers at higher levels (Vail, 1999).

A number of human resource issues are faced by hospitals. One of these is the people management of nurses. It is widely known that good people management can make a positive difference to the performance of the organisation. The effective management of nurses require that hospital executives understand the factors that influence the performance of nurses. Fisher, Schoenfeldt and Shaw (1996) maintain that the system an organisation uses to reward employees can play an important role in its efforts to gain competitive advantage and to achieve its major objectives. A hospital's compensation system may foster the achievement of the desired outcomes by motivating nurses and can link valued rewards to the performance of essential behaviours (Siddiqui \& Kleiner, 1998). The difficulty most hospital executives face in developing compensation systems is the heterogeneity of nurses employed within the hospitals. Lawler (1984) notes that such diversity means that managers must be sensitive to the need of blending potentially different approaches. But ultimately, a well managed training and development program will have long term advantages for a hospital, allowing for the improvement in the skills and abilities of nurses that will ultimately contribute to sustained levels of performance on the job for the benefit of the organisation. 


\section{Men and the Nursing Profession}

Nursing is unique in that during the late nineteenth century it became an almost completely 'feminised' occupation, following what Theweleit (1987) calls a 'new female assault' on medical and caring work. Hitherto, for centuries, men were at the forefront of the caring work. It was only in the mid-nineteenth century that nursing was given a feminine face as a result of the work of Florence Nightingale in the Crimean War (The World Book Encyclopaedia, 2001). In fact, Florence Nightingale is credited as the founder of the Nursing profession as we know it today (The World Book Encyclopaedia, 2001). A shift from masculinity to femininity occurred in the nursing profession from this time onwards. Before this, women did little more than midwifery. During the late twentieth century men increasingly found their way back into nursing. Modern nursing can be traced to the days of Florence Nightingale, who promoted the idea that to be a 'good nurse' was also to be a 'good woman' (Gamarnikow, 1978). Theweleit (1987) describes this ideal vision of the female nurse as the 'white nurse', a pure 'caring mother figure, who transcends sensuousness'.

Florence Nightingale was a strong advocate for both women and nursing, and considered certain traits such as nurturance, gentleness, empathy, compassion, tenderness and selflessness to be essentially feminine and essentially nurse-like. Not surprisingly, however, presently, this position has been increasingly challenged by those who argue that these attributes exist also in men, and might not necessarily be found in all female nurses (Wright \& Hearn, 1993). Despite the interest expressed in this area, there is almost always an acute nursing shortage around the world. Why? At some medical centres as many as one in five nursing slots is open. Largely as a result of the nursing shortage, salaries for nurses are spiralling upward (The Grant Doctor, 2002).

It might seem from a distance that male nurses are a numerical minority, but empirical studies suggest that they do not lose any of their structured male privilege that comes with engaging in paid work. For instance, Callah (2004) cites the work of the sociologist, Christine Williams, who examined men's experience in four female-dominated professions (nursing, elementary school teachers, librarians and social workers). She interviewed 76 men and 23 women in these professions in four metropolitan areas. She was so shocked by the findings (superior pay and privileges of male nurses, elementary school teachers, librarians, and social workers) that she coined a new term, the "Glass Escalator", to contrast this phenomenon with the 'glass ceiling'. The term 'glass escalator' has come to refer to a tiny minority in fields heavily female-dominated. These people are slowly changing the face of their professions.

The influx of men into nursing is driven in part by mounting unemployment situations. More male employees are now willing to consider new careers, even in fields that have long been considered women's work. And layoffs also make workers eager to move into female-dominated industries, such as child-care and nursing, where labour shortages offer more job security. At the same time, hospitals are launching staffing drives aimed at attracting male nurses due to the fact that hospitals find themselves facing both immediate and long-term shortages of personnel, including nurses (American Hospital Association [AHA], 2001).

As a result of the foregoing factors cited, there is a very definite shift going on into what has traditionally been a female-dominated area. The change is small but significant, career experts and economists say. The National Sample Survey of Nurses, compiled by the U.S. Department of Health and Human Services Division of Nursing, reports that the number of men in nursing rose from 4\% in 1992 to 5\% in 1996. The American Association of Colleges of Nursing reports that the number of men enrolled in baccalaureate nursing programs increased from $9.5 \%$ in 1992 to $11 \%$ in 1997 . The percentage of men in graduate programs jumped from $4.6 \%$ in 1992 to $7.8 \%$ five years later.

In other female-dominated fields it has also been noted that, there are more male legal assistants, too. In the US, men held $15.3 \%$ of those jobs in 2000 but nearly $18 \%$ in 2002 . Male telephone operators have jumped from $9.4 \%$ to $14.2 \%$. There have also been increases in male data-entry clerks, bank tellers, maids, dressmakers and early-childhood teachers. The number of men in private household work, doing jobs such as launderers, housekeepers, cooks and home child care, has also climbed from 3.8\% in 1983 
to $5.3 \%$ in 2002 (Armour, 2003). Boivin (2002), writing on men in military nursing, concluded that the chances of having an all-male team of registered nurses (RNs) is more than five times as likely to occur in the military. He reported that in the US Army $35.5 \%$ of the nurses are men.

Worldwide, the gender imbalance in nursing is more striking than in almost any other field of science: only $6 \%$ of RNs are men and nursing gender imbalance persists at the highest educational and technical levels. A search by the National Institute for Nursing Research (NINR) for Principal Investigators yielded 210 active persons: 183 women, 18 men, and nine scientists of indeterminate gender (The Grant Doctor, 2002). Approximately $5.4 \%$ of the 2.1 million RNs employed in nursing in the United States are men, according to the National Sample Survey of Registered Nurses (Health Resources and Services Administration, 1996).

Male nurses are sometimes preferred in hospitals because, rightly or wrongly, they have more physical stamina, and hence have less trouble "man-handling" patients, picking them up, moving them, etc. As Williams (2006) noted, male nurses find that their female colleagues automatically expect them to handle unruly or heavy patients. But do men get their just deserts when they join the nursing profession? This does not seem to be the case. According to the US Department of Labor, Women's Bureau (1997), cited by Jackson (2001), women hold 75 percent of all managerial positions in medicine and the healthcare system. Grant and Williams (2006) found that in 2000 , almost $13 \%$ of students enrolled in nursing school in the US were men. They also estimated that by mid 2006, men would make up approximately $5.4 \%$ of the 2.2 million nurses in the US.

\section{Nursing in Ghana}

Ghanaian nurses vary in age, socio-economic status, education, geographic location, and ethnic background. For the purposes of achieving the government's aim of 'health for all,' different categories of nurses are being trained and employed in Ghana. There is anecdotal evidence showing that nursing in Ghana is seriously handicapped by the fact that it lacks the numbers of specialists in common health services for the work on hand, and worse still, that the nursing education only trains nurses for hospital work with a serious imbalance in the supply of professional nurses in favour of the hospital nurse. Nursing encompasses health promotion, prevention and rehabilitation. Maglacas (1986) notes that nursing is institutional, individual, family, mental health and, increasingly, a proponent of self-care. Mathauer and Imhoff (2006) state that there is a serious shortage of human resources in the health sector of subSaharan African countries, including Ghana, a situation that threatens the realisation of plans for scaling up interventions to control the spread of diseases such as HIVIAIDS, malaria and tuberculosis.

The Ghana Registered Nurses Association Daily Graphic (2006a) in its annual 'Nurses Day' celebration appealed to the Ministry of Health to address the imbalance in the health sector workforce as well as the introduction of a performance-related reward system for nurses. For its part, the General Nursing Group (GNG) of Ghana in its annual conference Daily Graphic (2006b) identified a lack of appropriate training and skills, and a lack of simple medical equipment as some of the constraints affecting the healthcare delivery system in general and nursing in particular. The group stressed that without the training of nursing specialists and provision of enhanced working environment, the healthcare delivery system in Ghana would continue to face harsh challenges. They further suggested that nurses' career progression be streamlined to reflect their qualifications and responsibility.

The World Development Report (2004) states that without improvements to the human resources situation, the health-related Millennium Development Goals cannot be achieved. The report notes that the problems are multiple, the most serious being staff shortages, particularly in rural and remote areas. Mathauer and Imhoff (2006) suggest that especially for developing countries like Ghana, adequate human resource management (HRM) and quality management (QM) tools should be used to develop the work environment so that health workers like doctors and nurses are enabled to meet their personal and organisational goals. 


\section{DATA AND METHODOLOGY}

\section{Data}

The population for the study was taken from professional nurses who had worked in the field for at least five years after graduating from the School of Nursing, University of Ghana, Legon, Ghana. The sample was nurses working in both private and public/government health institutions including teaching hospitals, a military hospital, a psychiatric hospital, a police hospital and several large private hospitals. Most of the nurses were in the care field while a few of them were in the administrative sections of their establishments. The initial contact set was 120 nurses who were randomly selected from a list of students that graduated from the School of Nursing and working for at least five years. It was assumed that in five years an appreciable level of professional development and work-related enhancement would have been accomplished. Out of the total, 50 nurses comprising 21 males and 29 females working in various hospitals and health institutions responded. Graduates from the School of Nursing, University of Ghana were used because it was possible to obtain a record of graduates and their first duty stations. It was thus reasonable and expedient to use this sample population for the study. Active data were collected from September 2004 to March 2005.

\section{Methodology}

The study adopted an in-depth exploratory approach to operationalise the research questions. A detailed questionnaire made up of 21 items was developed. The design was therefore a cross-sectional approach in which data was sought from the respondents. Given the exploratory nature of the research and to answer the main research questions, a thematic analysis and clustering of findings from each question and section was executed. The data was captured using Statistical Package for Social Sciences (SPSS). A combination of descriptive accounts as well as summary statistics using chi-square and correlations are used to examine the findings. The chi-square measures test the hypothesis that the row and column variables in a cross tabulation are independent. A low significance value (typically below 0.05 ) indicates that there may be some relationship between the two variables. While the chi-square measures may indicate that there is a relationship between two variables, they do not indicate the strength or direction of the relationship. The symmetric (correlation) measures indicate both the strength and significance of the relationship. The value of each statistic can range from -1 to 1 , the low significance values indicating that there is a relationship between the two variables. But the low values for the test statistics indicate that the relationship between the two variables is a fairly weak one. A cross tabulation was also run to ascertain the number of cases in each category defined by two or more grouping variables. Cross tabulations are useful for summarising categorical variables -- variables with a limited number of distinct categories. For each value of a variable, a frequency table was created to display the number of times (count) that value occurred.

\section{FINDINGS}

\section{Findings: Qualitative}

The study found that $70 \%$ ( 23 females and 12 males out of the 50 respondents) rejected the notion that they were restricted in where they could work within the nursing field. While $82.75 \%$ of females believed the male nurse is not given more job responsibilities, $71.43 \%$ of males asserted that male nurses are given more job responsibilities. Also $76 \%$ of the respondents said that their gender was not unfairly affecting their career development opportunities. However, whilst $90 \%$ of females held this view, only $57 \%$ of males agreed with it. In trying to define the reasons for men's progression even in femaledominated fields, the perceptions, roles, competencies and qualities of women were of concern. One wonders if there is a preferred style of management that creates differences between females and males.

Different persons rarely do the same job in the same way and most jobs can be approached or organised in different ways in accordance with individual peculiarities. Thus a person identifies with a respected group, which leads to an interest in particular vocation. That is why Gattiker and Cohen (1997) concluded 
that $70 \%$ of the job-holders determine if an occupation is male or female. Thus the high percentage (74\%) of respondents in this study, who said they do not intend to leave the field because they have achieved their aim for joining the field, is interesting. This is absolutely contrary to the issue of role conflict among subjects (Reber, 1985). Without such deviants as males in female dominated fields, it will be difficult for individuals to cope with such influences as technology advances, war and contact with others cultures.

\section{Findings: Quantitative}

\section{Hypothesis I}

The gender of subjects was tested against whether they were restricted in any field or department within the nursing profession (that is, the areas where they can work in the hospitals) using cross tabulation. Out of 29 females, $79 \%$ said they were not restricted; $57 \%$ of males were of the same view. Thus a majority of respondents believe there are no restrictions, even among the males who are in the minority. This is shown in Table 1.

Table 1: Gender and restrictions in the nursing field

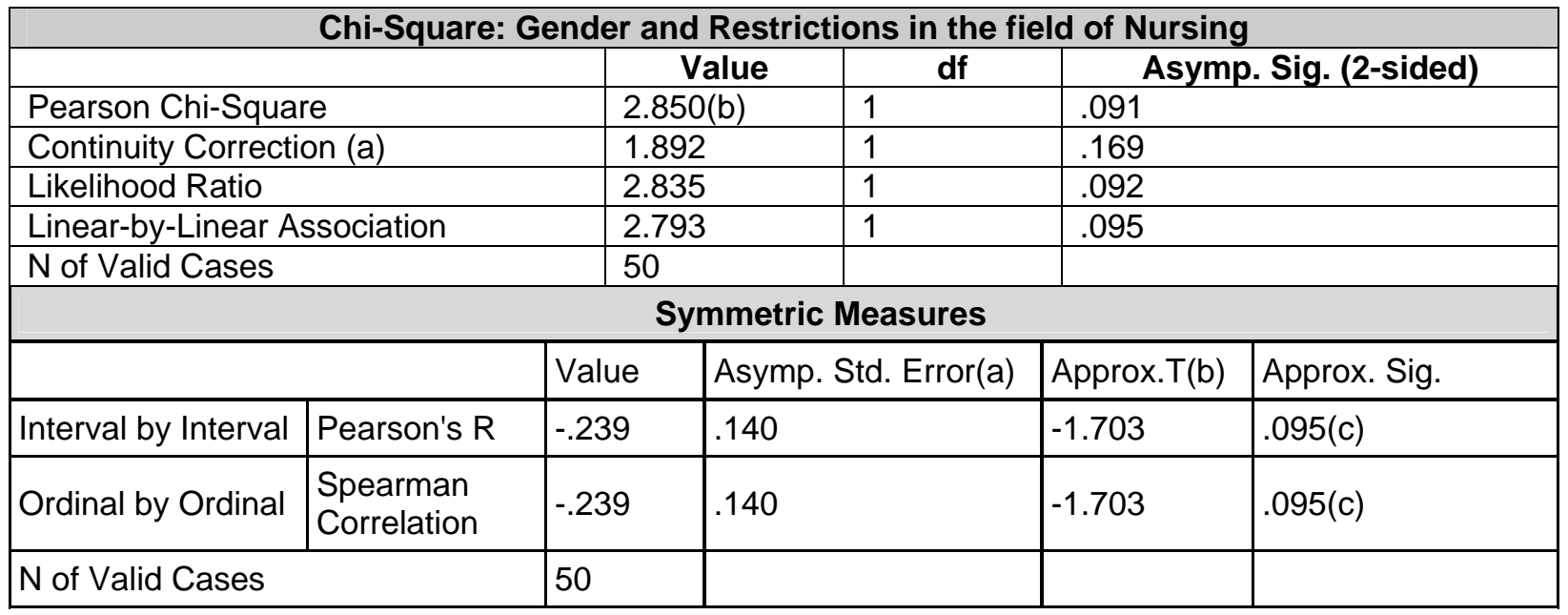

A further analysis using the chi square test (Table 1) indicates no relationship between the gender of subjects and the incidence of restrictions (0.095). This is confirmed by a negative or weak correlation (-.239) as shown in Table 1. This result does not support the first hypothesis, which stated that male nurses are discriminated against more than female nurses in the nursing field. In effect, male nurses are not discriminated against in the nursing field.

Respondents were also asked whether male nurses are given more job responsibilities. This was tested with gender. Seventy percent of males said 'yes' but only $17 \%$ of females said 'yes', [Table 2]. When this response was further tested with chi square and correlation measures, it showed a significant negative relationship (-.546), as in the symmetric measures (Table 2). This shows that when it comes to assigning responsibilities, male nurses are given more work than women nurses, indicating some level of discrimination. In this respect, male nurses are discriminated against, thus confirming Hypothesis I of this study.

The extent to which gender affects career development was also tested. The results indicate that, gender had no effect on career development, and that any difference observed was negligible. For instance, $57 \%$ of males and $79 \%$ of females said 'no' as shown in Table 3. The chi-square and correlation measures also showed negative relations (chi square: 0.010 , Pearson's R: 0.007 with a value of -0.376 ). The result, which is significantly negatively related, rejects hypothesis I. 
Table 2: Gender and differential job responsibilities

\begin{tabular}{|c|c|c|c|c|c|c|c|c|c|}
\hline \multicolumn{10}{|c|}{ Cross-Tabulation: Gender and Differential Job Responsibilities } \\
\hline \multirow{2}{*}{\multicolumn{5}{|c|}{ Variables and Dimension }} & \multicolumn{4}{|c|}{ Gender } & \multirow{2}{*}{ Total } \\
\hline & & & & & \multicolumn{2}{|l|}{ Female } & \multicolumn{2}{|c|}{ Male } & \\
\hline \multirow{2}{*}{\multicolumn{2}{|c|}{$\begin{array}{l}\text { Differential Job } \\
\text { Responsibilities }\end{array}$}} & \multicolumn{3}{|c|}{ Yes } & \multicolumn{2}{|l|}{5} & \multicolumn{2}{|r|}{15} & 20 \\
\hline & & $\bar{\Lambda}$ & & & \multicolumn{2}{|l|}{24} & \multicolumn{2}{|r|}{6} & 30 \\
\hline \multicolumn{4}{|c|}{ Total } & \multicolumn{3}{|c|}{29} & \multicolumn{2}{|r|}{21} & 50 \\
\hline \multicolumn{10}{|c|}{ Chi-Square Tests: Gender and Differential Job Responsibilities } \\
\hline & & & & \multicolumn{2}{|c|}{ Value } & \multicolumn{2}{|l|}{ df } & \multicolumn{2}{|c|}{ Asymp. Sig. (2-sided) } \\
\hline \multicolumn{4}{|c|}{ Pearson Chi-Square } & \multicolumn{2}{|c|}{ 14.901(b) } & \multicolumn{2}{|l|}{1} & \multicolumn{2}{|l|}{.000} \\
\hline \multicolumn{4}{|c|}{ Continuity Correction(a) } & \multicolumn{2}{|c|}{12.729} & \multicolumn{2}{|l|}{1} & \multicolumn{2}{|l|}{.000} \\
\hline \multicolumn{4}{|l|}{ Likelihood Ratio } & \multicolumn{2}{|c|}{15.512} & \multicolumn{2}{|l|}{1} & \multicolumn{2}{|l|}{.000} \\
\hline \multicolumn{4}{|c|}{ Linear-by-Linear Association } & \multicolumn{2}{|c|}{14.603} & \multicolumn{2}{|l|}{1} & \multicolumn{2}{|l|}{.000} \\
\hline N of Valid Cases & & & & 50 & & & & & \\
\hline & & & Symr & etric & Measures & & & & \\
\hline & & & Value & Asy & mp. Std. E & $\operatorname{or}(\mathrm{a})$ & & prox. T(b) & Approx. Sig. \\
\hline Interval by Interval & Pea & & -.546 & .120 & & & & 514 & $.000(\mathrm{c})$ \\
\hline Ordinal by Ordinal & $\begin{array}{l}\text { Spe } \\
\text { Cor }\end{array}$ & & -.546 & .120 & & & & 514 & $.000(\mathrm{c})$ \\
\hline $\mathrm{N}$ of Valid Cases & & & 50 & & & & & & \\
\hline
\end{tabular}

\section{Hypothesis II}

The second hypothesis tested was: The top positions in the nursing profession are occupied by males. When the various ranks in the nursing field were cross-tabulated with subjects' gender, it showed that more females occupied the top positions/ranks. It also showed that, whilst most of the respondents were of the 'Nursing Officer' rank, the females (48\%) outnumbered the males (38\%). That is, proportionately, more females occupied higher positions than males. [Table 4], thus rejecting Hypothesis II of this study.

Table 3: Gender and unfair career advancement opportunities in the nursing field

\section{Chi-Square Tests: Gender and unfair Career Advancement Opportunities in the Nursing Field}

\begin{tabular}{|c|c|c|c|c|c|c|}
\hline & \multicolumn{2}{|c|}{ Value } & df & \multicolumn{2}{|c|}{ Asymp. Sig. (2-sided) } \\
\hline & Pearson Chi-Square & \multicolumn{2}{|c|}{$7.059(b)$} & 1 & \multicolumn{2}{|l|}{.008} \\
\hline \multicolumn{2}{|c|}{ Continuity Correction (a) } & \multicolumn{2}{|c|}{5.389} & 1 & \multicolumn{2}{|l|}{.020} \\
\hline \multicolumn{2}{|l|}{ Likelihood Ratio } & \multicolumn{2}{|c|}{7.135} & 1 & \multicolumn{2}{|l|}{.008} \\
\hline \multicolumn{2}{|c|}{ Linear-by-Linear Association } & \multicolumn{2}{|c|}{6.917} & 1 & \multicolumn{2}{|l|}{.009} \\
\hline \multicolumn{2}{|c|}{$\mathrm{N}$ of Valid Cases } & \multicolumn{2}{|c|}{50} & & & \\
\hline \multicolumn{7}{|c|}{ Symmetric Measures } \\
\hline & & Value & \multicolumn{2}{|c|}{ Asy. Std. Error(a) } & App. T(b) & App. Sig \\
\hline Interval by Interval & Pearson's R & -.376 & .13 & & -2.809 & $.007(\mathrm{c})$ \\
\hline Ordinal by Ordinal & Spearman Cor & -.376 & .13 & & -2.809 & $.007(\mathrm{c})$ \\
\hline $\mathrm{N}$ of Valid Cases & & 50 & & & & \\
\hline
\end{tabular}


Table 4: Cross-tabulation: rank in nursing and Gender

\begin{tabular}{|c|c|c|c|c|c|c|}
\hline \multirow{2}{*}{\multicolumn{2}{|c|}{ Rank in Nursing }} & \multicolumn{3}{|c|}{ Gender } & \multirow{2}{*}{\multicolumn{2}{|c|}{ Total }} \\
\hline & & Female & & Male & & \\
\hline \multicolumn{2}{|l|}{ Staff Nurse } & \multicolumn{2}{|l|}{1} & 2 & \multicolumn{2}{|c|}{3} \\
\hline \multicolumn{2}{|l|}{ Senior Staff Nurse } & & & 1 & \multicolumn{2}{|c|}{1} \\
\hline \multicolumn{2}{|l|}{ Nursing Officer } & \multicolumn{2}{|l|}{14} & 8 & \multicolumn{2}{|c|}{22} \\
\hline \multicolumn{2}{|c|}{ Senior Nursing Officer } & \multicolumn{2}{|l|}{8} & 6 & \multicolumn{2}{|c|}{14} \\
\hline \multicolumn{2}{|c|}{ Principle Nursing Officer } & \multicolumn{2}{|l|}{4} & 2 & \multicolumn{2}{|c|}{6} \\
\hline \multicolumn{2}{|l|}{ Not stated } & \multicolumn{2}{|l|}{1} & 2 & \multirow{2}{*}{\multicolumn{2}{|c|}{$\frac{3}{49}$}} \\
\hline \multicolumn{2}{|l|}{ TOTAL } & \multicolumn{2}{|l|}{28} & 21 & & \\
\hline \multicolumn{7}{|c|}{ Chi-Square Tests Rank in nursing and Gender } \\
\hline & & \multicolumn{2}{|l|}{ Value } & df & \multicolumn{2}{|c|}{ Asymp. Sig. (2-sided) } \\
\hline \multicolumn{2}{|l|}{ Pearson Chi-Square } & \multicolumn{2}{|l|}{ 3.323(a) } & 5 & \multicolumn{2}{|l|}{.650} \\
\hline \multicolumn{2}{|l|}{ Likelihood Ratio } & \multicolumn{2}{|l|}{3.686} & 5 & \multicolumn{2}{|l|}{.595} \\
\hline \multicolumn{2}{|c|}{ Linear-by-Linear Association } & \multicolumn{2}{|l|}{.664} & 1 & \multicolumn{2}{|l|}{.415} \\
\hline \multicolumn{2}{|l|}{ No. of Valid Cases } & \multicolumn{3}{|l|}{49} & & \\
\hline & & Symmet & ic Mea & asures & & \\
\hline & & Value & Asy. & Std. Error(a) & App. T(b) & App. Sig. \\
\hline Interval by Interval & Pearson's R & .118 & .141 & & .812 & $.421(\mathrm{c})$ \\
\hline Ordinal by Ordinal & Spearman Cor & -.028 & .147 & & -.191 & $.849 @$ \\
\hline No. of Valid Cases & & 49 & & & & \\
\hline
\end{tabular}

The chi square measure indicated that there is no significant relationship between gender and rank/positions in the nursing field (correlation: 0.118); that is, males do not occupy the top positions in the nursing field in Ghana, thus rejecting hypothesis II.

Table 5: Gender and intention to leave the service

\begin{tabular}{|l|l|l|l|l|}
\hline \multicolumn{3}{|c|}{ Cross-Tabulation: Gender and Intention to Leave the Service } & \multirow{2}{*}{ Total } \\
\cline { 3 - 5 } \multicolumn{2}{|c|}{ Variables and Dimensions } & Female & Male & \\
\hline \multirow{2}{*}{ Intention to leave this job/position } & Yes & 7 & 9 & 16 \\
\cline { 2 - 5 } & No & 22 & 12 & 34 \\
\hline Total & 29 & 21 & 50 \\
\hline \multicolumn{2}{|c|}{ Chi-Square Tests: Gender and Intention to Leave the Service } \\
\hline \multicolumn{2}{|c|}{ Value } & df & Asymp. Sig. (2-sided) \\
\hline Pearson Chi-Square & $2.488(a)$ & 2 & .288 \\
\hline Likelihood Ratio & 2.837 & 2 & .242 \\
\hline Linear-by-Linear Association & .801 & 1 & .371 \\
\hline
\end{tabular}

A substantial number of the respondents intend staying on, though some have plans of leaving. For instance, $42.9 \%$ of males and $24.9 \%$ of females responded 'yes' to this question, showing that more males have the intention of leaving the field as compared to females (Table 5). On the whole, respondents indicated that their goals have been achieved to a large extent; $76 \%$ of females and $71 \%$ of males confirmed this. But interestingly, all the female nurses exhibit a desire to further their career, whilst 
$91 \%$ of males want to do the same. When achievement was tested with desire for further development of career, a negative relationship was realised (chi square: 0.74 , correlation: -0.085 ).

Other relevant variables were tested to investigate the possibility of discrimination and its effect on job satisfaction (Table 6). These included: the desire of the respondent to leave the field, satisfaction with the field/job, achievements and so on. 34 of the 50 respondents (representing 68\%) do not want to leave the field though they have not been promoted. There is however no relationship between the intent of leaving and being promoted.

Table 6: Promotion and intention to leave the service

\begin{tabular}{|l|l|l|l|l|l|}
\hline \multicolumn{5}{|c|}{ Cross-Tabulation: Promotion and Intention to Leave the Service } \\
\hline \multirow{2}{*}{ Variables and Dimensions } & \multicolumn{2}{|l|}{ Ever promoted since joining the service } & \multirow{2}{*}{ Total } \\
\cline { 2 - 5 } & Yes & No & 16 \\
\hline \multirow{2}{*}{$\begin{array}{l}\text { Intention to leave this job/position any } \\
\text { time soon }\end{array}$} & Yes & 6 & 10 & 34 \\
\cline { 2 - 5 } & No & 19 & 25 & 50 \\
\hline Total & 25 & df & Asymp. Sig. (2-sided) \\
\hline \multicolumn{4}{|c|}{ Chi-Square Tests: Promotion and Intention to Leave the Service } \\
\hline Pearson Chi-Square & Value & 2 & .321 \\
\hline Likelihood Ratio & $2.273(\mathrm{a})$ & 2 & .263 \\
\hline Linear-by-Linear Association & 2.670 & 2 & .300 \\
\hline N of Valid Cases & 1.076 & 1 & \\
\hline
\end{tabular}

\section{CONCLUSIONS}

The results show that generally, there is no discrimination in the nursing field in Ghana. But there is obviously a style of management in the nursing field that has created differences between female and male nurses and this is an ongoing process, a 'silent culture.' Many have asked the reasons for the preferences. The idea that to be a 'good nurse' was to be a 'good woman' (Gamarnikow, 1978:77-121), signifying 'a caring figure who transcends sensuousness' (Theweleit, 1987) is still being challenged since men also have such attributes (Wright \& Hearn, 1993). "Unlike in some occupations, nurses are most, if not always, working in a team, nothing like 'the best nurse' award", as expressed by one respondent. Just as in most occupations, there is a laid down procedure for advancement. To get promoted, a nurse has to serve a number of years, apply for promotion and go for an interview.

Yet discrimination against men may still linger in certain areas of nursing, such as obstetrics, gynaecology and psychiatry. Florence Nightingale believed that men's 'hard and horny' hands were not fitted 'to touch, bathe and dress the wounded' (Summers, 1988). It is thus not surprising that most male nurses are seen in orthopaedics, mental health care and in the theatre (most specialised in anaesthesia). This probably shows why only a few special programmes exist for bringing men into the field. Nonetheless, contrary to what pertains internationally, male nurses in this study report a very high level of job satisfaction even in this study; $74 \%$ achieved their aim and $66 \%$ had no intention of leaving the field.

Although there is little empirical data to support the existence of gender-specific recruitment, hiring or promotion practices, it is quite evident that males are in the minority in nursing in Ghana. Men in today's 
nursing world have to prove themselves just as women have to prove themselves in male-dominated professions. The study shows that though they are in the minority, male nurses are not discriminated against in any way, contrary to what pertains internationally. There are many other fields of human endeavour that are dominated by men; therefore there is nothing wrong with having one professional field that is dominated by women. The important thing is that discrimination on the basis of gender or any other factor should always be discouraged by all.

The 'Glass Escalator,' phenomenon of men in female dominated fields like nursing is evident in Ghana but the men are not pushed up to the top as suggested by Williams (1989, 1992, 1993, 1995). Male nurses enter a profession dominated by women and have to learn to get along with and in many cases take orders from women bosses. They find that moving up the ranks is difficult because their numbers are few and they find themselves victims of the same kinds of discrimination that women have for years fought for (Hilton, 2001).

There is a shortage of professionals in many sectors of the Ghanaian economy and the situation is no different in the nursing profession. At the same time, more males are entering those professions that were previously held to be the bastion of females. But clearly there are issues pertaining to men in female dominated professions like nursing. So what are the human resource implications of these findings for the Ghana healthcare system? It is clear that managers in the healthcare system, and particularly in hospitals, must increasingly recognise human resource as a strategic asset, different from but as important as adequate payment, capital acquisition and market share (AHA, 2001). Consequently, healthcare executives need to recognise that the supply, development and satisfaction of caregivers and supportive personnel of all ilk, including nurses, is a critical success factor for every organisation. The AHA (2001) suggests that hospitals must consider innovations that encourage their staff, including nurses to obtain additional training in order to facilitate career development and upward mobility, a point that is also emphasised by the Ghana Registered Nurses Association (Daily Graphic, 2006a).

The results identify areas of concern to nurses, both male and female. To resolve some of these challenges, the Ghana General Nursing Group (Daily Graphic, 2006b) has called for improved training of nurses in modern trends in nursing and other health procedures including the handling of modern medical equipment, drug dispensing, handling of patients and professional ethics. Mathauer and Imhoff (2006) in noting that human resource management tools can uphold and strengthen the professional ethos of doctors and nurses, also recommend the acknowledgement and professionalism of nurses as well as addressing their professional goals such as recognition, career development, further qualification, and the development of the work environment so that health workers are enabled to meet their personal and organisational goals. In this regard, both international and Ghanaian concerns coalesce.

To help resolve concerns of perceived discrimination regarding work assignments and pay, as well as nurse retention, the General Nursing Group (Daily Graphic, 2006b) suggests a reorganisation of the career progression of nurses in Ghana as they identify the existing career structure as one of the key constraints. For their part, Mathauer and Imhoff (2006) advocate the introduction and /or promotion of incentives and human resource management tools aimed at both individuals' aspirations and organisational changes. These include group-based performance awards and pay, effort-related awards and pay, team building, development of career development plans, transparent and reliable promotion schemes, performance management tools, and staff satisfaction surveys. Hodes research (2005:137) quotes a male nurse as noting that 'better gender balance in the nursing profession will enhance professional status, bring a fresh perspective to care, promote diversity, increase pay/benefits, and expand the influence of nursing in health care policy and decision-making.'

This study has only broached the subject. It would be useful to do a more expanded version: covering the whole country; all categories of nurses not only graduate nurses; using panel data over a longer period; and comparing perceptions in different employment sectors: public/private; different nursing sectors; generalist/specialist, and other such distinctions. 


\section{REFERENCES}

Abdul-Nasiru I \& Cofie E. 2002. The changing role of women in work organisations, in AkuamoahBoateng (Ed). Women's Career Issues. You and Psychology. Accra: Prudent Printing Press.

American Hospital Association [AHA]. 2001. Workforce supply for hospitals and health systems issues and recommendations. Developed by the AHA Strategic Policy Planning Committee. Approved as a statement of interim positions by the AHA Board of Trustees [Online] Available from: http://www.aha.org/aha/issues/workforce/workforceB0123.html.Homepage [Accessed: 05/11/2006].

Armour S. 2003. More men train to be nurses, midwives, secretaries. USA Today [Online] Available from: http://www.usatoday.com/money/workplace/2003-07-10-gender_x.htm [Accessed: 04/10/2004].

Boivin J. 2002. Men make their mark in military nursing. Nursing Spectrum Homepage [Online] Available from: http://community.nursingspectrum.com/MagazineArticles/article.cfm?AID=7906 [Accessed: 12/03/2006].

Callah J. 2004. Male Nurses Riding The Glass Escalator [Online] Available from: http://www.listprintbucknell.ed/archives/femecon-1/200404/msg00043.html

Chung V. 2006. Men in nursing [Online] Available from: http://www.minoritynurse.com/features/nurse_emp/08-03-00c.html [Accessed: 29/11/2006].

Daily Graphic. 2006a. Nurses urged to avoid strike actions. Tuesday, September 26:31. Accra: Graphic Communications Group.

Daily Graphic. 2006b. Nurses urged to refrain from extortion. Wednesday, November 1:14. Accra: Graphic Communications Group.

Fisher C, Schoenfeldt L \& Shaw J. 1996. Human Resource Management. Boston: Houghton Mifflin.

Gamarnikow E. 1978. Sexual Division of Labour: The Case of Nursing, in Kuhn \& Wolpe (eds) Feminism and Materialism: Women and Modes of Production. London: Routledge and Kegan Paul. Pp 77-100, 105-107, 121

Gattiker U \& Cohen A. 1997. Gender-based wage differences: The effects of occupation and job segregation in Israel. Industrial Relations, 52:507-530.

Grant E \& Williams R. 2006. Men in Nursing [Online] Available from:

www.unctv.org/ncnursing/meninnursing.html-homepage [Accessed: 07/05/2006].

Health Resources and Services Administration. 1996. Nursing Workforce Reports \& Data. 'The Registered Nurse Population \& Findings from the 1996 national Sample Survey of Registered Nurse.' [Online] Available from:

http://bhpr.hrsagov/healthworkforce/reports/nursing/samplesurvey00/chapter1.htm [Accessed: 07/05/2006].

Hilton L. 2001. A few good men: male nurses defy stereotypes and discrimination to find satisfaction in a female-dominated profession. Nurseweek [Online] Available from:

http://www.nurseweek.com/news/features/01-05/men.html [Accessed: 05/11/2006].

Hodes Research. 2005. Men in Nursing. http://aamn.org/menInNursing2005Survey.pdf 1.26.05.131-137. Date accessed 2.29.07

Hultin M. 2003. Occupational Sex Segregation. Work and Occupations, 30(1):30-61 
Jackson JC. 2001. Women middle managers' perception of the glass ceiling. Women in Management Review, 16(1):30-41.

Kirchmeyer C. 1998. Determinants of managerial career success: Evidence and explanation of male/female differences. Journal of Management, 24: 673-692.

Lawler E. 1984. The Strategic Design of Reward Systems. New Mexico: Fornburn.

Lindgren G. 1992. Doctors, nurses and girls. Stockholm: Carlssons.

Maglacas AM. 1986. Nurses must look towards the future. International Nursing Review [INR], 33(6): 178-9.

Mathauer I \& Imhoff I. 2006. Health worker motivation in Africa: the role of non-financial incentives and human resource management tools. Human Resources for Health, (4)24:1-17.

Maume DJ. 1999. Glass ceilings and glass escalators. Work and Occupations. 26(4):483.

Reber AS. 1985. Dictionary of Psychology. Brooklyn, NY: Penguin Books Ltd.

Reed Business Information (RBI). 1999. [Online] Available from: http://www.reedbusiness.com/us.html [Accessed: 04/10/2004].

Siddiqui J \& Kleiner B. 1998. Human resource management in the health-care industry. Health Manpower Management, 24(4):143-147.

Stroh L, Brett J \& Reily A. 1992. All the right stuff: A comparison of female and male managers' career progression. Journal of Applied Psychology, 77:251-260.

Summers A. 1988. Angels and Citizens: British Women as Military Nurses 1854-1914. London: Routledge and Kegan Paul.

Tharenou P, Latimer S \& Conroy D. 1994. How do you make it to the top? An examination of influences on women's and men's managerial advancement. Academy of Management Journal, 37:899-931.

The GrantDoctor. 2002.The GrantDoctor: Men in Nursing [Online] Available from: grantdoctor@aaas.org [Accessed: 07/05/2006].

The World Book Encyclopaedia. 2001. [Online] Available from: www.worldbook.com/wb/article?id=ar391480 st=Florence+nightingale\#cite [Accessed: 04/10/2004].

Theweleit K. 1987. Male Fantasies I: Women, floods, bodies, history. Trans. Stephen Conway in collaboration with Erica Carter and Chris Turner. Cambridge: Polity Press.

Vail K. 1999. A few good men. American School Board Journal, 186(10):28-30.

Watson F. 1995. Organisational behaviour and gender. London: McGrawHill

White B. 1995. The career development of successful women. Women in Management Review, 10(3):415.

Williams CL. 1989. Gender differences at work: Women and men in non-traditional occupations. Berkeley: University of California Press. 
Williams CL. 1992. The glass escalator: Hidden advantages for men in the 'female' professions. Social Problems, 39(3):253-267.

Williams CL. (Ed.). 1993. Doing “women's work: men in non-traditional occupations. Newbury Park, CA: Sage.

Williams CL. 1995. Still a man's world. Men who do women's work. Berkeley: University of California Press.

Williams D. 2006. Looking for a Few Men [Online] Available from: http://www.allnurses.com/forms/f212 [Accessed: 29/11/2006].

World Bank: World Development Report. 2004: Making Services Work for Poor People. Washington, DC 2003.

Wright CJ \& Hearn J. 1993. Paper delivered at the 'Nursing, Women's History and Politics of Welfare' conference. Nottingham: University of Nottingham. 